\title{
Notas
}

\section{Avanços da regionalização nas Américas: cronologia analítica}

\author{
PAULO ROBERTO DE ALMEIDA Y YVES CHALOULT
}

\section{Introdução}

A presente cronologia analítica dos processos de regionalização nas Américas tem objetivos didáticos, quais sejam, o de evocar sumariamente, com vistas a uma informação e análise sintéticas dirigidas aos pesquisadores, as principais etapas do processo de integração regional e suas linhas externas de afiliação institucional.

Ela foi concebida com base em quatro dimensões relevantes: a) as origens e o desenvolvimento da idéia integracionista, desvendando as conexões conceituais e organizacionais entre as experiências européias e latino-americanas nesse área, no contexto do sistema multilateral de comércio; b) a integração na América Latina, com ênfase na modelização institucional do Mercado Comum do Sul (Mercosul), cujo processo de formação apresenta características historicamente inéditas e politicamente inovadoras; c) o processo de integração na América do Norte, através da consolidação do Acordo de Livre Comércio da América do Norte (Nafta); d) o processo de integração hemisférica, através de uma futura Área de Livre Comércio das Américas (Alca), em via de negociação.

\section{Origens e desenvolvimento da idéia integracionista}

1889-90: Realização, a convite dos Estados Unidos, da primeira Conferência Internacional Americana, em Washington, de outubro de 1889 a março de 1890 . O governo norte-americano tinha em mira conformar uma união comercial das Américas, unificar procedimentos aduaneiros e de pagamentos, estabelecer regras para a propriedade intelectual e permitir investimentos em infra-estrutura.

1939-41: Novas tentativas dos EUA com vistas a concretizar uma zona de compensações hemisférica, ao abrigo dos esquemas interamericanos de tipo defensivo concebidos na fase inicial da guerra européia. As propostas são, porém, recusadas pelos países latino-americanos. 
1944-47: Conferência monetária e financeira de Bretton Woods, em que se decide pela criação do Fundo Monetário Internacional (FMI) e do Banco Internacional de Reconstrução e Desenvolvimento (Bird); reuniões preparatórias visando constituir uma Organização Internacional do Comércio, terceiro pilar do sistema concebido em Bretton Woods.

Bélgica, Luxemburgo e Países Baixos, através do Tratado de Londres e do Protocolo de Haia, decidem constituir uma união aduaneira conhecida como Benelux.

1947-48: Nas conferências interamericanas de Petrópolis e de Bogotá, os países latino-americanos reclamam um plano Marshall para a região; em resposta, os EUA recomendam a abertura desses países ao investimento estrangeiro privado.

Conferência sobre Comércio e Emprego das Nações Unidas, em Havana, decide pela criação de uma Organização Internacional do Comércio; diversos países latino-americanos apoiam a constituição de "zonas de preferências comerciais", mas outros, adotando as posições multilateralistas norte-americanas, demonstram reservas em relação ao tema. O Acordo Geral sobre Tarifas Aduaneiras e Comércio (Gatt), negociado pouco antes em Genebra e contendo cláusulas exclusivamente comerciais, tinha previsto em seu artigo 24 apenas o estabelecimento de zonas de livre comércio e de uniões alfandegárias, tomando por base o modelo e a experiência nascente do Benelux.

1948: São criadas a Comissão Econômica para a Europa, da Organização das Nações Unidas (ONU), e a Organização Européia de Cooperação Econômica (OECE), órgão de coordenação destinado a administrar a distribuição da ajuda norte-americana no quadro do Plano Marshall, de recuperação econômica européia. 1950-51: Memorando Monet e Plano Schuman lançam o processo de integração na Europa ocidental, mediante o Tratado de Paris, criando a Comunidade Européia do Carvão e do Aço (Ceca), que promove a administração comum dos recursos carboníferos e da produção siderúrgica de França, Alemanha, Benelux e Itália e adota o modelo até então inédito do direito comunitário. A Europa também institui, no quadro da OECE e sob regulação do Banco de Compensações Internacionais (BIS), uma união de pagamentos, mas as moedas só serão livremente conversíveis no final daquela década.

1956: Os países europeus começam a pensar em formas mais avançadas de integração, segundo o modelo comunitário criado pela Alta Autoridade do Tratado da Ceca.

1957: Assinatura do Tratado de Roma, constituindo o Mercado Comum Europeu. 1957-59: Na Europa, restabelece-se a livre conversibilidade das moedas, em uma situação de relativa estabilidade das paridades cambiais, segundo o modelo definido em Bretton Woods em 1944. 


\section{A integração na América Latina}

\subsection{Perspectiva histórica}

1948: A Comissão Econômica das Nações Unidas para a América Latina e o Caribe (Cepal), que havia acabado de ser criada, defende a idéia da integração regional, mencionando, em uma Resolução, a possibilidade de uma "união aduaneira" na América do Sul.

1956: A Cepal volta a defender a formação de um "mercado regional" sulamericano como forma de acelerar o processo de industrialização. O intercâmbio intra-regional se liberaliza um pouco, com a adoção de acordos de tipo multilateral, mas a escassez de divisas fortes impõe limites aos fluxos comerciais.

1957-58: A assinatura e entrada em vigor do Tratado de Roma provocam grande repercussão na América Latina. Autoridades diplomáticas e econômicas dos países da região começam a considerar a idéia de uma "zona de preferências tarifárias" no Cone Sul, envolvendo a Argentina, o Uruguai e o Chile, países entre os quais era mais intenso o intercâmbio comercial. Em virtude das disposições restritivas do Gatt (artigo 24), tem-se, contudo, de passar diretamente ao modelo da zona de livre comércio.

1957-59: Reunidos em Genebra, os representantes latino-americanos começam a reclamar a introdução de disposições especiais para os países em desenvolvimento no âmbito do Gatt, sob a égide de um novo regime de concessões não submetidas ao princípio da reciprocidade.

1958-59: O Brasil articula o lançamento da "Operação Pan-Americana" de cooperação hemisférica, de forte conteúdo econômico. Início do processo negociador da integração regional na América do Sul.

1960: Assinatura do Tratado de Montevidéu, criando a Associação LatinoAmericana de Livre Comércio (Alalc), baseado fundamentalmente em projeto dos quatro países do Cone Sul e com o objetivo último de constituir um mercado comum regional, a partir da conformação de uma Zona de Livre Comércio, em um prazo de 12 anos, de conformidade com as regras do Gatt.

1960-64: Negociação multilateral, na Alalc, de "listas comuns" e "listas nacionais", produto a produto, de reduções tarifárias e eliminação de restrições não-tarifárias, para a ampliação dos mercados, a liberalização do intercâmbio e o desmantelamento das medidas protecionistas vigentes no intercâmbio regional.

1962: Cuba solicita sem sucesso seu ingresso na Alalc. Sob pressão dos EUA, a Conferência de Punta del Este, a despeito da oposição de diversos países da região, decide por sua exclusão do sistema interamericano.

1964: Primeira Conferência das Nações Unidas sobre Comércio e Desenvolvimento (Unctad) e reforma do Gatt, com a introdução de uma Parte IV, especificamente sobre Comércio e Desenvolvimento, abrindo caminho para o 
estabelecimento de um sistema de preferências em favor dos países em desenvolvimento sem obrigação de reciprocidade.

1964-69: Paralisação do processo negociador multilateral para a definição de "listas comuns" na Alalc; políticas fortemente protecionistas (tarifas altas e restrições não-tarifárias) e desentendimentos políticos entre os países-membro. No plano do sistema comercial multilateral, avança-se no sentido de reconhecer a especificidade dos países em desenvolvimento (Parte IV do Gatt e Sistema Geral de Preferências, com tratamento concessional e não recíproco).

1964-80s: Onda de regimes militares na América Latina e tendências substitutivas nas políticas econômicas (de industrialização e de comércio exterior) dos países da região afetam negativamente o processo integracionista. Enquanto os países asiáticos começam uma lenta inserção na economia internacional, os países latinoamericanos recuam relativamente em sua participação no comércio internacional. 1965: Assinatura do Convênio sobre Créditos e Pagamentos Recíprocos (CCPR), criando um sistema de compensação de pagamentos entre os países membros da Alalc, instrumento extremamente útil para a poupança de divisas.

1967: Conferência de Chefes de Estado e de Governo americanos em Punta del Este proclama o objetivo de se constituir um "mercado comum latino-americano" em um prazo máximo de 15 anos, a partir de 1970.

1968-69: Primeiras fissuras no sistema de Bretton Woods e crises monetárias no continente europeu levam os responsáveis políticos a considerar a utilidade de um aprofundamento do processo de integração comercial, inclusive em sua dimensão monetária. O Relatório Werner, em 1970, propõe o objetivo de uma união monetária em um prazo de dez anos.

1969: A clivagem entre países "comercialistas" (Argentina, Brasil e México) e "desenvolvimentistas" (Bolívia, Chile, Colômbia, Equador e Peru) faz com que estes últimos, sem abandonar formalmente a Alalc, decidam criar o Grupo Andino, através do Acordo de Cartagena, baseado no modelo do direito comunitário. A Venezuela adere em 1973 e o Chile, vivendo sob um regime militar de orientação econômica liberal, abandona o Grupo Andino em 1976.

1969-75: O Grupo Andino evolui de forma bastante dinâmica em suas fases iniciais, com o estabelecimento de programas de desgravação tarifária, tarifa externa mínima comum, tratamento uniforme para o capital estrangeiro, regime comum sobre patentes, organismo de financiamento e programas setoriais de desenvolvimento industrial, instituição de um Tribunal de Justiça, de uma Comissão, da Junta e do Parlamento Andino. Entretanto, o caráter ambicioso do programa integracionista, aliado à recessão econômica que sacudiu a América Latina a partir da crise do petróleo (e, posteriormente, da dívida), levou a uma desaceleração das metas propostas em 1969.

1970: Revisão necessária do programa de liberalização no âmbito da Alalc, com prorrogação até 1980 do período previsto para a implementação de uma zona de livre comércio. 
1970-80: A necessidade de expansão das exportações para zonas de moedas fortes e as restrições às importações provocam grande queda nos fluxos de comércio intra-regional e a exacerbação do modelo de substituição das importações. A Alalc é utilizada como alavanca dos processos de industrialização nacional. O pensamento geopolítico, então em voga na região, descartava a idéia de qualquer cessão de soberania em favor de um projeto integracionista, visto como manobra da esquerda latino-americana para enfraquecer o "poder nacional" ou a "solidariedade americana".

1971: A desvinculação do dólar do padrão-ouro definido em Bretton Woods provoca enormes repercussões mundiais (inclusive a nacionalização do petróleo e a correção radical de seus preços), criando uma interação dinâmica relativamente inédita entre inflação e desemprego nas economias avançadas.

1973-79: Vários países em desenvolvimento são afetados pela duplicação do preço do petróleo, mas passam a receber empréstimos em petrodólares (pelos quais pagam juros flutuantes) reciclados pelo sistema financeiro internacional em expansão.

1979: A Rodada Tóquio de negociações comerciais do Gatt aprova o princípio do tratamento preferencial e mais favorável para os países em desenvolvimento: cláusula de habilitação permite a outorga e o intercâmbio recíproco de preferências comerciais parciais, com a derrogação admitida da cláusula de nação-maisfavorecida.

1980: Assinatura do Tratado de Montevidéu que institui a Associação LatinoAmericana de Integração (Aladi), no quadro de amplo processo de reestruturação dos objetivos, compromissos e modalidades da integração econômica na região. Eliminou-se a obrigação de elaboração de listas comuns, abandonou-se a fixação de prazos para o cumprimento das metas integracionistas (zona de livre comércio ou mercado comum) e passou-se a mecanismos mais flexíveis, de caráter bilateralista, para a conformação de uma "área de preferências tarifárias".

1982-85: Crise da dívida externa na maior parte dos países latino-americanos e prosseguimento das políticas protecionistas. A Preferência Tarifária Regional, instituída em 1984 na Aladi, tem níveis meramente simbólicos, produzindo reduzido efeito comercial. O comércio regional que, a despeito das dificuldades existentes, havia alcançado o nível mais elevado de sua história em 1981 (24 bilhões de dólares), enfrenta forte queda e apenas voltaria a se recuperar em princípios da década seguinte.

1986: Declaração de Punta del Este, que dá início à Rodada Uruguai de Negociações Comerciais Multilaterais do Gatt (e processo paralelo para os serviços); previstas para durar quatro anos, elas se estenderão até 1993. Na Europa, o Ato Único das Comunidades Européias prevê a constituição de um mercado unificado dentro de seis anos, o que efetivamente ocorreu em $1^{\circ}$ de janeiro de 1993. 
1991: Chile e México firmam na Aladi um acordo de liberalização do comércio; o Grupo dos Três (G3) começa negociações para a liberalização do intercâmbio entre Colômbia, Venezuela e México. Diversas outras iniciativas, na região andina, na América Central e no Caribe, relançam a integração continental, em bases subregionais.

1998: Cuba é aceita como $12^{\circ}$ país-membro da Aladi, depois de participar, como observador, de seus trabalhos desde 1986.

\subsection{As origens do Mercado Comum do Sul (Mercosul): relações Argentina- Brasil}

1941: Brasil e Argentina fazem um ensaio de "união aduaneira", sem resultados efetivos em virtude de diferenças políticas e diplomáticas que se manifestam entre os dois países depois do ataque japonês a Pearl Harbor e de tomada de atitudes distintas em relação às potências do Eixo. $\mathrm{O}$ comércio é regulado por acordos estritamente bilaterais, com aplicação limitada e condicional da cláusula da naçãomais-favorecida.

1950-53: Tentativas frustradas de aproximação política e econômica entre o Brasil, a Argentina e o Chile (novo "pacto ABC"): elas encontram a oposição de correntes pró-americanistas e antiperonistas nesses países.

1959: Reaproximação Brasil-Argentina, depois de um largo período de afastamento recíproco, introduz um programa limitado de cooperação econômica e abre a via para o estabelecimento da Alalc. Os regimes militares nos anos 60 empreendem projetos de capacitação nuclear.

1975-79: Negociação do tratado bilateral Brasil-Paraguai, constituindo Itaipu Binacional para a exploração da hidroeletricidade do Rio Paraná: fase caracterizada por grandes rivalidades político-militares e econômico-comerciais entre os países da região, sobretudo entre o Brasil e a Argentina, que passam a se enfrentar diplomaticamente a propósito do aproveitamento dos recursos hídricos da bacia do Paraná. O tema seria equacionado no final da década, por acordo tripartite, abrindo espaço para que a confrontação fosse superada, mais adiante, pela cooperação econômica e pelo entendimento político, no quadro dos processos de redemocratização política.

1985: "Declaração de Iguaçu", pela qual os presidentes civis da Argentina e do Brasil expressam sua "firme vontade de acelerar o processo de integração bilateral" e criam, para tal fim, uma Comissão Mista de Alto Nível, presidida pelos ministros de Relações Exteriores dos dois países. Na mesma ocasião, firma-se uma "Declaração Conjunta sobre Política Nuclear", que proclama os propósitos pacíficos da cooperação bilateral nessa área.

1986: "Ata para a Integração Brasil-Argentina", estabelecendo, segundo modalidades baseadas na complementação industrial, o Programa de Integração e 
Cooperação Econômica (PICE), de caráter "gradual, flexível e equilibrado" e prevendo tratamentos preferenciais frente a terceiros mercados; diversos protocolos setoriais são assinados bilateralmente.

1988: "Tratado de Integração, Cooperação e Desenvolvimento" entre o Brasil e a Argentina, com o objetivo de consolidar o processo de integração bilateral e instituir, em uma primeira etapa, um espaço econômico comum no prazo máximo de dez anos e a harmonização das políticas aduaneiras, comercial, agrícola, industrial e de transportes e comunicações, assim como a coordenação de políticas monetária, fiscal e cambial; em uma segunda etapa, proceder-se-ia à harmonização gradual das demais políticas necessárias à formação do mercado comum.

1990: "Ata de Buenos Aires", assinada em 6 de julho, pela qual os presidentes da Argentina e do Brasil decidem conformar o mercado comum bilateral até 31 de dezembro de 1994, estabelecem uma metodologia apropriada para tal fim (reduções tarifárias generalizadas, lineares e automáticas, eliminação de barreiras nãotarifárias) e criam o Grupo Mercado Comum, de caráter binacional. Na mesma ocasião, é firmado o Tratado para o Estabelecimento de um Estatuto das Empresas Binacionais Brasileiro-Argentinas.

Acordo de Complementação Econômica (ACE) n ${ }^{\circ} 14$, firmado em dezembro pelos representantes da Argentina e do Brasil junto à Aladi, consolidando no âmbito desta Associação o programa de liberalização comercial concertado no Tratado de Integração, nos prazos definidos pela Ata de Buenos Aires (até 31.12.94), dando início a um processo de consultas e negociações com outros países da região com vistas à ampliação do processo de liberalização comercial entre o Brasil e a Argentina.

O Uruguai e o Paraguai, na qualidade de observadores, começam a participar de reuniões entre Brasil e Argentina.

\subsection{Criação e consolidação do Mercosul}

1991: Assinatura, em 26 de março, do Tratado de Assunção, visando à constituição de um mercado comum entre a Argentina, o Brasil, o Paraguai e o Uruguai. O tratado definiu um programa de liberalização comercial de todo o universo alfandegário em um período de transição até 31 de dezembro de 1994 e adotou os mecanismos de caráter intergovernamental já fixados no programa bilateral BrasilArgentina, assim definidos: Conselho, órgão supremo, de natureza intergovernamental; Grupo Mercado Comum, órgão executivo, coordenando as atividades de 11 Subgrupos de trabalho; Comissão Parlamentar Conjunta, com representantes designados por cada Parlamento nacional.

"Acordo relativo a um Conselho sobre Comércio e Investimentos" entre os quatro países do Mercosul e os EUA (junho). 
"Protocolo de Brasília para a Solução de Controvérsias" (dezembro): mecanismo ad hoc de solução arbitral dos conflitos comerciais entre os paísesmembro do Mercosul, adotado na I Reunião do Conselho do Mercado Comum (CMC). O Mercosul não cria um direito comunitário e continua a privilegiar o "modelo Benelux" de caráter intergovernamental, de preferência a um sistema de tipo supranacional como o europeu.

1991-94: O Mercosul cria órgãos subsidiários e reuniões de ministros, entre elas a de ministros da Economia e presidentes de Bancos Centrais (anterior à própria vigência do Tratado de Assunção), da Educação (Plano Trienal para o Setor), da Justiça, do Trabalho, da Agricultura; cria ainda diversas reuniões especializadas: de meio ambiente, de cultura, de ciência e tecnologia, de turismo, etc. Tem lugar intensa atividade de harmonização das legislações internas, de integração aduaneira e de adoção de normas e regulamentos técnicos comuns para a livre circulação de bens no território dos Estados-membro. Os países membros passam a coordenar suas posições nos foros econômico-comerciais internacionais e o Grupo Mercado Comum (GMC) define critérios comuns para a negociação de acordos parciais de comércio no âmbito da Aladi.

1992: Assinatura do Tratado de Maastricht, criando a União Européia (UE) e prevendo inclusive uma união monetária naquele continente. Através do “Acordo de Cooperação Interinstitucional entre a Comissão das Comunidades Européias e as instituições do Mercosul" é formalizado um diálogo entre os chanceleres das duas regiões.

A II Reunião do CMC adota, pela Decisão 1/92, um extenso programa de medidas ("Cronograma de Las Leñas") para o cumprimento dos compromissos fixados no Tratado de Assunção, isto é, a conformação do "Mercado Comum do Sul" até 31 de dezembro de 1994; o GMC fica encarregado de adotar um cronograma de medidas adicionais para o pleno funcionamento do Mercosul em $1^{\circ}$ de janeiro de 1995 (alguns prazos serão prorrogados no decurso dos trabalhos). A Decisão 3/ 92 aprova o procedimento de reclamações e consulta sobre práticas desleais de comércio (dumping e subsídios), e a Decisão 5/92 um protocolo de cooperação e assistência judiciária em matéria cível, comercial, trabalhista e administrativa.

Criação da "Comissão Sindical do Mercosul", por iniciativa da Coordenadora de Centrais Sindicais do Cone Sul (CCSCS), entidade constituída em 1986, congregando centrais sindicais dos quatro países membros, além do Chile e da Bolívia; pelo Brasil, participam a Central Única dos Trabalhadores (CUT), a Confederação Geral dos Trabalhadores (CGT) e a Força Sindical (FS). Começa a se reunir o Subgrupo de Trabalho (tripartite) n 11 (SGT-11), Assuntos Trabalhistas, posteriormente denominado "Relações Trabalhistas, Emprego e Seguridade Social". Diversas entidades do setor propõem, a par de um Foro Social, uma Carta dos Trabalhadores do Mercosul, sistematizando princípios básicos na área social e trabalhista. Ulteriormente, o governo brasileiro declarou ser favorável à adoção de 
uma Carta de Direitos Fundamentais, mas se opõe à vinculação de questões comerciais com as trabalhistas.

1993: Resolução (7/93) cria, no âmbito do GMC, o Grupo Ad Hoc sobre Aspectos Institucionais, encarregado de formular propostas sobre a futura arquitetura jurídica do Mercosul (artigo 18 do Tratado). Mercosul e Banco Interamericano de Desenvolvimento (BID) firmam convênio de cooperação técnica não-reembolsável, destinado à realização de estudos técnicos e de projetos de consultoria sobre reconversão produtiva.

Conclusão, em dezembro, das negociações dos acordos multilaterais da Rodada Uruguai; o Mercosul é objeto de atento exame, ainda em curso, pelas Partes Contratantes, por meio de Grupo de Trabalho no âmbito do Comitê de Comércio e Desenvolvimento.

1993-94: Negociação da Tarifa Externa Comum (TEC) no Mercosul: diferenças de estrutura e de níveis de desenvolvimento industrial entre o Brasil e os demais parceiros resultam na aceitação, durante uma "fase de convergência" (até 20012006), de listas nacionais de exclusão (para bens informáticos e de capital, por exemplo). Os países-membro também decidem harmonizar os incentivos às exportações, respeitando disposições do Gatt.

1994: Assinatura, em Marraquesh, dos resultados das negociações comerciais da Rodada Uruguai, com a criação da Organização Mundial do Comércio (OMC), em funcionamento a partir de $1^{\circ}$ de janeiro de 1995.

A VI Reunião do CMC aprova diversos instrumentos reguladores do mercado comum em construção: protocolos sobre integração educacional, promoção e proteção de investimentos externos e jurisdição internacional em matéria contratual; acordo sobre transporte de mercadorias perigosas; regulamento sobre regime de origem. O CMC também cria a Comissão de Comércio do Mercosul (CCM), de caráter intergovernamental, destinada a administrar a futura união aduaneira; em sua primeira reunião (6-7/10), a CCM aprova seu regimento interno, definindo reuniões mensais.

Em 17 de dezembro, é assinado o "Protocolo de Ouro Preto", que modifica parcialmente o Tratado de Assunção e dá personalidade jurídica internacional ao Mercosul. Na ocasião, a VII reunião do CMC aprova, além de listas nacionais de produtos em regime de adequação final à união aduaneira (com prazos adicionais para sua integração à TEC), diversos atos internacionais: acordo sobre transporte multimodal, código aduaneiro, protocolo de medidas cautelares, protocolo sobre promoção e proteção recíprocas de investimentos e acordo bilateral Brasil-Argentina sobre internação de bens de zonas francas.

A nova estrutura institucional definida no Protocolo de Ouro Preto (que ainda permanece intergovernamental) compreende os seguintes órgãos:

1. Conselho do Mercado Comum (CMC);

2. Grupo Mercado Comum (GMC); 
3. Comissão de Comércio do Mercosul (CCM);

4. Comissão Parlamentar Conjunta (CPC);

5. Foro Consultivo Econômico-Social (FCES);

6. Secretaria Administrativa do Mercosul (SAM).

As Decisões do Conselho, as Resoluções do GMC e as Diretrizes da CCM constituem fontes jurídicas do Mercosul e são obrigatórias, de direito, para os Estados membros; todos os órgãos são igualitários; a tomada de decisão se faz por consenso; a coordenação principal se dá entre os ministérios das relações exteriores dos quatro países.

"Declaração Solene Conjunta entre o Mercosul e a União Européia", em 22 de dezembro, em Bruxelas, prevendo a negociação, em 1995, de um AcordoQuadro Inter-Regional de Cooperação Econômica, conduzindo, em última instância, à liberalização do comércio entre as duas regiões.

1995: Entrada em vigor, em $1^{\circ}$ de janeiro, da União Aduaneira (em implementação) do Mercosul.

Reunião especializada de ministros da Cultura do Mercosul, em Buenos Aires (15/03), lança o "Mercosul Cultural", com a assinatura de Protocolo prevendo o funcionamento de sete comissões.

Encontro entre os ministros das Relações Exteriores do Mercosul e da União Européia (UE), no dia 17 de março, em Paris, reafirma o objetivo de se chegar a um amplo espaço de cooperação e de integração unindo ambas as entidades.

Firmado, em dezembro, o Acordo-Quadro de Cooperação Inter-Regional entre a UE e o Mercosul, em Madri: a liberalização comercial "deverá levar em conta a sensibilidade de certos produtos" (referência à Política Agrícola Comum) e as regras da OMC.

1996: Assinada a Declaração Presidencial sobre Compromisso Democrático no Mercosul pela qual os quatro países assumem o compromisso de consultarem-se e de aplicarem medidas punitivas, dentro do espaço normativo do Bloco, em caso de ruptura ou ameaça de ruptura da ordem democrática em algum Estado-membro. Os presidentes assinam também uma declaração sobre diálogo político, estabelecendo um mecanismo de consulta e de concertação política mútua.

1997: Acordo Brasil-Argentina, em novembro, decide elevar a Tarifa Externa Comum em três pontos percentuais, medida a ser implementada pelos quatro países membros até 31 de dezembro de 2000.

Acordo-Quadro sobre serviços, dependente da negociação de protocolos setoriais para a liberalização de setores específicos.

1998: Difíceis negociações para a definição de um regime automotivo comum entre os países do Mercosul e para a liberalização do setor açucareiro: este é protegido na Argentina, que, por sua vez, acusa o Brasil de subsidiá-lo. 
A Comissão Européia, principal órgão executivo da UE, decide propor ao Conselho dos 15 Ministros iniciar negociações com o Mercosul e o Chile com o intuito de desenvolver uma associação inter-regional, estabelecendo, entre outros objetivos, uma zona de livre comércio.

Assinatura da Declaração Sócio-Laboral do Mercosul, criando um Comitê Tripartite, pelos quatro presidentes do Mercosul, durante a reunião semestral do CMC, no Rio de Janeiro, em dezembro.

1999: Em março, criação da Comissão Sócio-Laboral do Mercosul pelo Resolução $\mathrm{N}^{\circ} 15 / 99$ do GMC. Essa comissão que não tem poder sancionador e funcionará através de recomendações diretas ao GMC, dependerá sobretudo da ação política e da pressão sindical para ampliar o seu papel e transformá-la efetivamente em um espaço de negociação, levando para o GMC as questões sociais.

Em abril, assinatura do primeiro "Contrato Coletivo de Trabalho no Mercosul", entre a Volkswagen do Brasil e da Argentina e os sindicatos dos metalúrgicos destes dois países, estabelecendo os princípios básicos de relacionamento entre capital e trabalho no âmbito do Mercosul.

Em maio, reunião e declaração, no Rio de Janeiro, das centrais sindicais latino-americanas, caribenhas e européias para discutir e encaminhar propostas de medidas significativas para alcançar o progresso social, no que tange aos processos de integração em curso.

Em junho, realização, no Rio de Janeiro, da primeira Conferência de Cúpula ou Cimeira entre os Chefes de Estado e de Governo da América Latina, do Caribe e da União Européia, com vistas a estreitar os laços de cooperação e de integração econômica entre as duas regiões. Na declaração final, assinada no dia 29 de junho, os Chefes de Estado e de Governo se comprometeram a avançar na consolidação de uma parceria estratégica entre as duas regiões, de caráter político, econômico e sócio-cultural.

Em junho, assinatura de um comunicado conjunto entre o FCES do Mercosul e o Comitê Econômico e Social das Comunidades Européias (CES), defendendo a cooperação interinstitucional, o fortalecimento da dimensão social nos acordos de cooperação existentes, a participação das instituições representativas da sociedade civil nos processos de negociação e, finalmente, a criação de um Comitê Consultivo Misto, formado pelo FCES e o CES, como já existe em outros acordos da UE com outros espaços econômicos.

Em junho, assinatura da declaração do Rio de Janeiro pelo "Fórum da Sociedade Civil para o Diálogo Europa, América Latina e Caribe", defendendo a construção de uma "Aliança Social Continental" entre organizações sociais e sindicais dos países das três Américas e da UE.

Em agosto, reuniu-se pela primeira vez o Grupo para a Coordenação de Políticas Macroeconômicas. 
No decorrer do ano, foram emitidos os primeiros laudos que resultaram da utilização completa do sistema arbitral do Mercosul (Protocolo de Brasília), tendo sido apreciados casos relativos às licenças de importação e barreiras à carne suína brasileira por parte da Argentina. Uma outra disputa entre os dois países, relativa a salvaguardas argentinas no setor têxtil, estava sendo conduzida no âmbito do órgão de solução de controvérsias da OMC.

2000: Definição e estabelecimento da política automotiva comum do Mercosul. 2001-05: Processo de convergência das últimas exceções à TEC do Mercosul.

\section{4. Área de Livre Comércio Sul-Americana (Alcsa)}

1993: Em outubro, durante a VII Reunião dos Presidentes do Grupo do Rio, realizada em Santiago, Chile, o Presidente do Brasil (Itamar Franco) lança a idéia de formação de uma Área de Livre Comércio Sul-Americana (Alcsa) que incluiria os países do Mercosul, da Comunidade Andina (CAN) e o Chile.

1995: Encontro dos presidentes do Cone Sul em Brasília, no dia 2 de janeiro: Bolívia e Chile começam a negociar sua associação ao Mercosul, capacitando-se a participar como observadores nas instâncias técnicas do Mercosul.

1996: Assinatura de acordos de Associação do Chile e da Bolívia ao Mercosul, ocorrendo antes do início da negociação de acordos semelhantes com países da CAN.

1998: Os países do Mercosul e da CAN assinam em Buenos Aires, em abril, um Acordo-Quadro que prevê a criação de uma zona de livre comércio entre os dois Blocos a partir de janeiro de 2000.

1998-99: Negociações entre o Mercosul e a CAN de um acordo de preferências tarifárias sobre a base do patrimônio histórico, mas que pode incluir produtos novos. Esse acordo deve substituir os de alcance parcial existentes entre os países das duas regiões.

1999: Em julho, o Brasil e os membros da CAN alcançaram um acordo sobre tarifas preferenciais sobre 2.728 produtos, que tornou-se efetivo em agosto.

\section{O processo de integração na América do Norte}

1985: Início de negociações entre os EUA e o Canadá, em março, visando elaborar um acordo de livre comércio entre os dois países, a exemplo do acordo assinado entre os EUA e Israel no mesmo ano.

1986: Em Quebec, Canadá, a Coalizão Quebecquense de Oposição ao Livre Comércio (CQOL), formada pelas principais centrais sindicais do Estado, é constituída e começa a atuar, iniciando uma tomada de posição de várias entidades contra o acordo; essa posição se estendeu, posteriormente, à toda a América do Norte. 
1987: É formado o Pro-Canada Network contra o Acordo; essa coalizão passou a se chamar Action Canada Network.

1988: O Acordo de Livre Comércio Estados Unidos-Canadá (CUSFTA) é assinado, no dia 2 de janeiro, pelos dois Chefes de Governo e, posteriormente, é ratificado pelo Congresso ou Parlamento dos dois países.

O Partido Progressista Conservador do Canadá ganha as eleições daquele ano, tendo como principal plataforma e proposta as vantagens da implementação do acordo de livre comércio com os EUA.

1989: O CUSFTA entra em vigor em $1^{\circ}$ de janeiro.

1990: Em abril, inicia-se o debate, no México, sobre um futuro acordo de livre comércio com os EUA.

Em junho, os presidentes do México, Carlos Salinas de Gortari, e dos EUA, George Bush, anunciam a sua intenção de negociar um acordo de livre comércio entre os dois países.

O Primeiro-ministro do Canadá, Brian Mulroney, pede ao presidente dos EUA para participar das discussões em andamento entre o México e os EUA, embora as relações comerciais do Canadá com o México sejam pouco significativas. 1991: Em fevereiro, o Canadá começa a participar do processo de discussão em curso.

Em junho, iniciam-se as negociações formais do futuro Acordo de Livre Comércio da América do Norte (Nafta).

No México, uma grande coalizão, chamada Rede Mexicana de Ação frente ao Livre Comércio (RMALC), é formada a fim de ampliar a oposição ao futuro acordo e de conduzir uma reflexão sobre a redação de um acordo alternativo.

1992: O movimento sindical dos EUA combate intensamente o futuro acordo.

Em dezembro, conclusão das negociações e assinatura do Nafta.

1993: Ratificação do Nafta pelos Poderes Legislativos dos três países.

Em setembro, assinatura de dois acordos paralelos ao Nafta: o Acordo Norte-Americano de Cooperação sobre o Trabalho (Anact) e o Acordo NorteAmericano de Cooperação sobre o Meio Ambiente (Anacma), devido aos esforços do governo dos EUA, pressionado pelos movimentos ambientalistas e sindicais do país.

1994: O Nafta e seus dois acordos paralelos entram em vigor em $1^{\circ}$ de janeiro. 1995: A crise monetária mexicana de dezembro de 1994 abala o Nafta e provoca repercussões no resto da região.

No México, a RMALC submete a uma consulta pública, por meio do Referendo da Liberdad, um programa econômico alternativo para o México; mais de 400 mil pessoas participam da consulta.

O Congresso dos EUA nega a autorização para o Executivo negociar, chamada fast track, o ingresso do Chile no Nafta, o que incita esse país a se aproximar mais do Mercosul. 
1999: O Chile reafirma o seu desejo de se integrar ao Nafta e inicia as negociações neste sentido, embora o Congresso norte-americano não tenha aprovado o fast track para este fim.

\section{O processo de integração hemisférica: a Área de Livre Comércio das Américas (Alca)}

1990: "Iniciativa para as Américas", lançada em junho pelo Presidente George Bush para acompanhar as transformações políticas e econômicas em curso na América Latina e oferecer uma nova modalidade de relacionamento dos EUA com a região, centrada no comércio, nos investimentos e na solução do problema da dívida, e com vistas a se chegar a uma Zona de Livre Comércio Hemisférica, estendendo-se do Alasca à Terra do Fogo. Os primeiros passos nesse sentido serão dados com o México.

1994: Cúpula das Américas, de 9 a 11 de dezembro, em Miami: a declaração final dos chefes de Estado proclama o objetivo de negociar uma Área de Livre Comércio Hemisférica até 2005; a Organização dos Estados Americanos (OEA), a Cepal e o BID atuam como suporte técnico e apoio de secretaria.

1995: Primeira reunião ministerial do processo de integração hemisférico, em Denver, em junho, onde são constituídos sete grupos de trabalho para preparar o início das negociações, "equilibradas e abrangentes" (a serem concluídas até 2005), sobre a base dos acordos sub-regionais existentes e de forma plenamente compatível com as obrigações existentes na OMC.

1996: II Reunião Ministerial, realizada em Cartagena, Colômbia, em março: quatro grupos adicionais de trabalho são constituídos e é proclamado o objetivo de "progressos concretos" até o final do século.

1997: III Reunião Ministerial, realizada em Belo Horizonte, em maio: criou um Grupo de Trabalho sobre Solução de Controvérsias, mas não logrou definir o formato, cronograma e organização das negociações. Os países do Mercosul tomam posições como Bloco e não individualmente. Na ocasião foi realizado encontro de negócios, o Foro Empresarial, que vem tendo significativo sucesso na ampliação do intercâmbio em toda a região. O chanceler brasileiro sugere a criação de um Fórum Sindical com a finalidade de ampliar a participação na Alca, mas a idéia é vetada por alguns países.

Reunião da primeira Conferência Parlamentar das Américas com a presença de mais de 600 parlamentares de 35 países das Américas e do Caribe, incluindo Cuba, no Quebec, Canadá, em setembro. Os parlamentares pedem uma maior participação, a diversos níveis, no processo de negociação da Alca e analisam, em particular, as dimensões sociais, políticas e culturais da integração em curso. Na sua Declaração Final, insistem na importância de diminuir o déficit democrático do processo em curso. 
Reunidos em Guanacaste, Costa Rica, de 28 a 30 de outubro, os viceministros responsáveis pelo comércio no hemisfério examinam os progressos havidos nos preparativos para a abertura do processo de negociação da futura Alca.

O Congresso dos EUA nega o fast track ao Executivo que, assim, não tem "autoridade" para negociar com uma posição de força junto aos 33 outros países.

1998: IV Reunião ministerial do processo de integração hemisférica, em março, em São José, Costa Rica, com definição do formato, da agenda negociadora e dos locais e presidências sucessivas do processo de negociação (Comitê e nove grupos de negociação), tendo-se como base os princípios da transparência, da participação e da decisão consensual. Paralelamente, realizaram-se o IV Foro Empresarial e um encontro acadêmico sobre o tema da integração hemisférica, reunindo intelectuais da região.

Os nove Grupos de Negociação são os seguintes: Acesso a Mercados; Agricultura; Serviços; Investimentos; Subsídios, Anti-Dumping e Medidas Compensatórias; Políticas de Concorrência; Compras Governamentais; Direitos de Propriedade Intelectual; e Solução de Controvérsias.

II Cúpula das Américas, em abril, em Santiago do Chile, com Declaração Política dos Presidentes e Plano de Ação, cujos principais temas são a educação, o livre comércio, a democracia e os direitos humanos e a erradicação da pobreza.

Em maio, o Comitê de Acompanhamento da Conferência Parlamentar das Américas se reúne em San Juan, Porto Rico, e sugere que o Brasil organize e presida a II Conferência Parlamentar.

Reunião do Comitê de Negociação Comercial, em Buenos Aires, em junho, onde se discute, entre vários assuntos, uma forma através da qual os trabalhadores possam participar mais ativamente dos destinos da Alca, contribuindo para a democratização do processo. O Chanceler brasileiro externaliza as reservas do Bloco Mercosul em relação ao timing do processo de integração, que, segundo ele, afigura-se acelerado.

O Congresso dos EUA nega de novo o fast track ao governo do Presidente Clinton em setembro.

Nova reunião do Comitê de Negociação Comercial, em Paramaribo, em dezembro, para tratar de medidas de facilitação de negócios.

1999: Em novembro, V reunião ministerial da Alca, em Toronto, Canadá, onde discute-se, entre outros assuntos, a realização da III Cúpula das Américas no Canadá.

2000-01: Realização da III Cúpula das Américas no Canadá.

2003-05: Brasil e Estados Unidos exercem a co-presidência das negociações, na fase final e decisiva do processo de discussão da Alca. 
2005: Término hipotético das negociações hemisféricas para a conformação, a partir de 2006, da Alca. Se bem sucedida a negociação, o processo de implementação de uma zona de livre comércio hemisférica pode delongar-se por mais de dez anos, pelo menos.

Possível prazo, também, para o início de um acordo de associação entre o Mercosul e a UE.

Outubro de 1999 